\title{
Geometric Optimization of a Gas Turbine Blade Cooling Passage using CFD
}

\author{
Ussama Ali $^{a}$, Muhammad Sajid Kamran ${ }^{a}$ \\ ${ }^{a}$ Department of Mechanical Engineering, University of Engineering and Technology, Lahore, 54890, Pakistan
}

\begin{abstract}
This work focuses on the rib-turbulated cooling which is a category of impingement cooling and aims at optimizing the geometry of rib-roughened cooling passage of a gas turbine blade. CFD analysis is carried out using Ansys/Fluent to solve the steady RANS equations. Computational domain consists of a long rectangular channel with the length of the channel being 9 times its height. Ratios of rib width, rib height and rib pitch to hydraulic diameter of the channel are taken as 0.1 , 0.1 and 1.2, respectively. Numerical simulations are performed to analyze the performance of various rib shapes for Reynolds number, based upon the hydraulic diameter, in a range of 5000 to 50,000 . Uniform heat flux of $800 \mathrm{~W} / \mathrm{m}^{2}$ is applied to the ribbed wall. Incompressible air is used as the cooling fluid. Turbulent flow conditions are applied to the channel geometry with $k-\omega$ turbulence model. The effect of rib cross-section and rib pitch to rib width ratio on the heat transfer and friction factor is observed. The 2D CFD analysis revealed that the presence of ribs has significant effect on thermo-hydraulic performance of the cooling channel. Introducing square ribs in a smooth channel caused the Nusselt number to increase by two-folds. The highest value of Nusselt number was achieved by incorporating right-angle triangular ribs which caused the Nusselt number to increase by further $8 \%$, as compared to the square ribs, and an increase in friction factor of $2.5 \%$. The lowest value of friction factor was observed in semicircular ribs (2.95\% less than the square ribs), however, the Nusselt number also decreased by $1.5 \%$, as compared to square ribs. Decreasing rib pitch to rib width ratio increased both the Nusselt number and friction factor for all the cases. For square ribs, decreasing this ratio from 15 to 9 resulted in the rise of Nusselt number by $50 \%$ and increase in friction factor by $54 \%$.
\end{abstract}

Keywords: Gas turbine blade cooling, Obstructed flow, Heat transfer enhancement, Turbulators, Ribbed channel.

\section{Introduction}

Cooling passages are provided in machine parts where heat generation occurs, and this generated heat needs to be removed to avoid the damage or failure of the machine due to the thermal stresses. Internal cooling channels are found inside the gas turbine blades, high temperature propulsion systems, electric generator coils, cylindrical lining of IC engines and many other applications. For a gas turbine, cooling of the blades is achieved through bypass air bled from the last stages of the compressor which acts as a coolant. The cooling air is fed to the internal cooling channels of the turbine blades, where it removes heat from the hot surfaces, keeping temperatures within the thermal limits of the alloys used. To avoid the blade damage and to improve the turbine efficiency, optimum cooling channel

${ }^{*}$ Corresponding author. Tel.: +923458633347

E-mail: ussama.ali@uet.edu.pk

(c) 2016 International Association for Sharing Knowledge and Sustainability

DOI: $10.5383 /$ ijtee.17.02.004 geometry is essential. Various methods of turbine blade cooling include film cooling, impingement cooling and pin fin cooling. Rib-turbulated cooling is a subcategory of impingement cooling in which ribs are used to enhance the heat transfer. Turbulators such as ribs, dimples, spiral flutes, and smooth protrusions are some of the important types of surface alteration methods which have been used for over three decades in the industries [1]. Turbulators, such as ribs, break the flow near the wall surface and cause an increase in the turbulence. The amount of turbulent kinetic energy induced depends upon various factors such as rib shape, rib-height, rib-width, and rib-pitch etc., out of which rib shape is one of the most important factors. The penalty of such passive augmentations inside the flow channel is that there is an excessive pressure drop inside the channel.

Various researchers have done a detailed experimental research highlighting the importance of rib configuration and arrangement on the heat transfer and friction loss performance of the cooling channel. Gao and Sunden [2] investigated 
experimentally the consequence of rib configuration on the heat transfer and pressure loss behavior of the cooling channels. Various rib configurations were tested. Cooling channel with rectangular cross-section was used whose aspect ratio was varied from 1 to 8 . They concluded that the heat transfer characteristics were greatly influenced by the flow patterns caused by the inclined ribs. Islam et al. [1] experimentally studied the fluid flow behavior in a ribbed passage with a rectangular cross-section for two rib pitch to rib height ratios: 10 and 20 , with constant rib height at Reynolds numbers of 7000 and 20,000. In their results, turbulence kinetic energy showed no improvement by varying the rib pitch to height ratio. Chandra et al. [3] performed experiments and studied the heat transfer performance and friction loss behavior on a cooling passage with rectangular cross-section incorporated with transverse ribs on the channel walls. They found that there was a rise in heat transfer performance and friction loss as the quantity of ribbed walls increased. Experimental study was performed by Han and Park [4] on the heat transfer in passages with rectangular crosssection with turbulators placed on the walls. Rib attack angles used in their study were $30^{\circ}, 45^{\circ}, 60^{\circ}$ and $90^{\circ}$. The concluded that heat transfer performance was approximately $30 \%$ higher in square channel (aspect ratio of 1) with angled ribs as compared to transverse ribs, but the heat transfer performance was only $5 \%$ higher in rectangular channel (aspect ratio of $2 \& 4$ ) with angled ribs as compared to transverse ribs.

Numerical analysis techniques have proved to be very handy in this area of research. York et al. [5] executed unsteady RANS analysis of heat transfer performance in a cooling passage roughened by ribs. Their results depicted that the heat transfer parameters on the ribbed wall became nearly constant when the flow was fully developed in the stream-wise direction. Thianpong et al. [6] experimentally investigated heat transfer and friction factor for turbulent flow through a passage with varying heights of isosceles triangular ribs for Reynolds number in the range of 5000 to 20,000 . Their results suggested that uniform rib height performed better than the non-uniform one, and the in-line rib arrangement performed better than the corresponding staggered one.

Various studies have been carried out to investigate the effect of rib cross-sectional shape on the heat transfer performance and friction loss. Wang and Sunden [7] experimentally examined the heat transfer and friction loss behavior of different shaped ribs in a cooling passage with square cross-section for Reynolds number varying from 8000 to 20,000. The various cross-sectional shapes of ribs tested were: square, equilateral-triangular, and trapezoidal. The highest heat transfer performance was shown by trapezoidal ribs with decreasing height. Kamali and Binesh [8] took forward the research of Wang and Sunden [7] and carried out a numerical analysis of the exact same shapes as used by Wang and Sunden. They concluded that trapezoidal ribs with decreasing height showed the highest value of heat transfer performance. Promvonge and Thianpong [9] performed experimental investigation to study the heat transfer performance in cooling passages integrated with different rib shapes. The rib shapes tested were: rectangular, right-angle triangular, isosceles triangular and reverse right-angle triangular. The best heat transfer performance was displayed by right-angle triangular ribs while the worst heat transfer performance was revealed by reverse right-angle triangular ribs. Eiamsa-ard and Promvonge [10] experimentally investigated the effect of using rib-groove combination turbulators on the heat transfer and friction factor. They reported that the performance index was highest for the rib-groove combination, but it decreased with increasing Reynolds number. Chaube et al. [11] conducted a study using different geometric rib shapes (semicircular, circular, rectangular, and chamfered) in a rectangular channel of a solar air heater with a great aspect ratio of 7.5, integrated with ribs on the lower wall. In their results, they found that the highest Nusselt number was achieved by utilizing chamfered ribs, but the best performance index was shown by rectangular ribs.

Wongcharee et al. [12] performed numerical simulations to investigate the effect of rib cross-sectional shape on the heat transfer and friction factor in a cooling passage of rectangular cross-section. Ribs with various cross-sectional shapes were tested. Their results showed that the ribs with triangular crosssection gave maximum value of heat transfer for the Reynolds number ranging from 3000 to 7000 . Furthermore, the ribs with a concave front face showed better heat transfer performance in comparison to the ribs with convex frontal face. Manca et al. [13] numerically investigated the effect of rib shape in a cooling passage with transverse ribs installed on a single wall. Their results showed that there was a linear increase in the Nusselt number as Reynolds number was increased for all the values of rib pitch to rib width ratios. For square ribs, the maximum value of Nusselt number was obtained at pitch to width $(p / e)$ ratio of 12 and that for triangular ribs was obtained at the value of 10 . Manca et al. [14] performed computational analysis on the cooling channel incorporated with ribs of different shapes. The rib shapes analyzed were: square, triangular, rectangular, isosceles trapezoidal and rectangular trapezoidal. Their results showed that triangular ribs gave highest value of heat transfer parameter. Jia and Sunden [15] investigated the heat transfer performance and friction loss behavior numerically using square, semicircular, and deformed ribs in $2 \mathrm{D}$ channels. Their results showed that the distorted semicircular ribs can provide equivalent cooling with $30 \%$ less pressure drop across the channel as compared to that of square ribs. Shokouhmand et al. [16] investigated the heat transfer performance with rectangular channels with grooves as turbulators. Rectangular shaped and arc shaped groove were used in their analysis. Their results showed that channels incorporated with arc shaped grooves had higher values of Nusselt number as compared to channels with rectangular grooves. Moon et al. [17] numerically studied friction factor and heat transfer performance in a rectangular cooling passage with various rib shapes. Sixteen cases were tested in their analysis and the best performance was shown by boot-shaped rib, as it gave the best compromise between the heat transfer and friction loss across the passage.

The present study is aimed at investigating the forced convective flow in the turbulent regime and the heat transfer characteristics of a cooling channel integrated with various rib shapes. The performance of new rib shapes, which are not previously tested, is analyzed and compared with the conventional shapes already present in the literature.

\section{Computational Domain}

Fig. 1 shows a simple illustration of a ribbed channel incorporated with square ribs. The cooling channel has a crosssectional shape of a square (aspect ratio of 1) and hydraulic diameter $D_{h}$ equal to $50 \mathrm{~mm}$. Cooling passage is taken to be 460 $\mathrm{mm}$ long. At the bottom surface of the cooling passage, transverse ribs were placed with pitch to hydraulic diameter $\left(p / D_{h}\right)$ ratio of 1.2. Rib height $(h)$ and rib width $(e)$ are taken as $5 \mathrm{~mm}$ each, giving a blockage ratio of 0.1 .

Commercial software Ansys/Fluent was used for the numerical analysis of the two-dimensional ribbed channel. Wang and Sunden's [7] experimental setup was used as a reference to set the boundary conditions for this computational analysis. At the inlet, uniform $x$-velocity was implemented corresponding to a Reynolds number of 20,000. The Reynolds 
number was taken according to the hydraulic diameter of the passage. Temperature at the inlet was assumed to be $298 \mathrm{~K}$ and the inlet turbulence intensity was quantified as $5.0 \%$. The following relation [18] was used to calculate the turbulence intensity at the inlet:

$I=0.16 \operatorname{Re}^{-1 / 8}$

where $I$ is the turbulence intensity and $R e$ is the Reynolds number based on the hydraulic diameter of the channel. A zero static pressure was assumed at the outlet. On the ribbed wall a constant heat flux of $800 \mathrm{~W} / \mathrm{m}^{2}$ was applied. All the walls were set to no-slip condition and all the walls except the ribbed wall were assumed to be adiabatic.

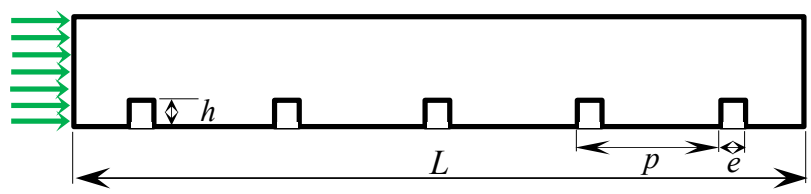

Fig. 1. Flow domain showing a cooling passage with square ribs
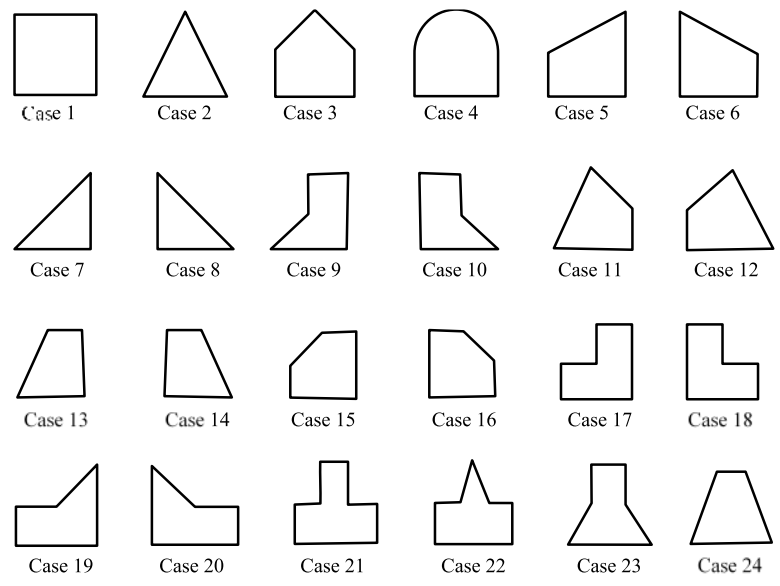

Fig. 2. Rib shapes tested in this work

The assumptions made for the numerical analysis are given in the following:

- The rib-roughened passage works under steady state conditions.

- The working fluid (air) is assumed to be incompressible for the flow regime.

- The fluid works in a single phase throughout the passage.

- Properties of passage material and of fluid are independent of the temperature.

- Uniform heat flux is applied on the ribbed wall.

\section{Governing Equations}

Governing equations needed to solve the flow are given as [19]: Continuity Equation:

$\frac{\partial}{\partial x_{i}}\left(\rho u_{i}\right)=0$

where $\rho$ is the density of the fluid, and $u_{i}$ is the axial velocity.

Momentum Equation: $\frac{\partial}{\partial x_{j}}\left(\rho u_{i} u_{j}\right)=-\frac{\partial P}{\partial x_{i}}+\frac{\partial}{\partial x_{j}}\left[\mu\left(\frac{\partial u_{i}}{\partial x_{j}}+\frac{\partial u_{j}}{\partial x_{i}}-\frac{2}{3} \delta_{i j}+\frac{\partial u_{i}}{\partial x_{j}}\right)\right]+$

$\frac{\partial}{\partial x_{j}}\left(-\rho \overline{u_{i}^{\prime} u_{j}^{\prime}}\right)$

where $\mu, u_{\mathrm{j}}$ and $\dot{u}$, are the viscosity of the working fluid, axial velocity and the fluctuated velocity respectively, and the turbulent shear stress is represented by $\left(-\rho \overline{u_{i}^{\prime} u_{j}^{\prime}}\right)$.

Energy Equation:

$\frac{\partial}{\partial x_{i}}\left[u_{i}(\rho E+P)\right]=\frac{\partial}{\partial x_{j}}\left[\left(k+\frac{C_{P} \mu_{t}}{P r_{t}}\right) \frac{\partial T}{\partial x_{j}}+u_{i}\left(\tau_{i j}\right)_{e f f}\right]$

where $\mathrm{E}$ is the total energy represented by: $E=C_{P} T+\frac{P}{\rho}+\frac{u^{2}}{2}$

$\operatorname{Pr}_{t}$ is the turbulent Prandtl number, and $\left(\tau_{i j}\right)_{e f f}$ is the deviatoric stress tensor, defined as:

$\left(\tau_{i j}\right)_{e f f}=\mu_{e f f}\left(\frac{\partial u_{j}}{\partial x_{i}}+\frac{\partial u_{i}}{\partial x_{j}}\right)-\frac{2}{3} \mu_{e f f} \frac{\partial u_{i}}{\partial x_{j}} \delta_{i j}$

A suitable turbulence model is required to resolve the RANS equations for incompressible steady flow. Seo et al. [20] tested two low-Re turbulence models; $k-\omega$ and Shear Stress Transport (SST). The low Reynolds $k$ - $\omega$ model [21] has some advantages over SST model such that the solver equations are less stiff near to the wall. The Shear Stress Transport (SST) model developed by Menter [22] combines the $k-\varepsilon$ and $k$ - $\omega$ models in such a way that $k-\varepsilon$ model is used in the region far from the wall and $k-\omega$ model is activated near the walls. In the research conducted by Seo et al. [20], $k-\omega$ turbulence model showed the best agreement with the experimental data. The two additional equations that need to be solved for the $k-\omega$ turbulence model are given by Wilcox [23] as:

Turbulence kinetic energy $(k)$ :

$\frac{\partial(\rho k)}{\partial t}+\frac{\partial\left(\rho u_{j} k\right)}{\partial x_{j}}=\rho P-\beta^{*} \rho \omega k+\frac{\partial}{\partial x_{j}}\left[\left(\mu+\sigma_{k} \frac{\rho k}{\omega}\right) \frac{\partial k}{\partial x_{j}}\right]$

where $\mathrm{P}$ is the total pressure given as: $P=\tau_{i j} \frac{\partial u_{i}}{\partial x_{j}}$

Specific rate of dissipation $(\omega)$ :

$\frac{\partial(\rho \omega)}{\partial t}+\frac{\partial\left(\rho u_{j} \omega\right)}{\partial x_{j}}=\frac{\gamma \omega}{k} P-\beta \rho \omega^{2}+\frac{\partial}{\partial x_{j}}\left[\left(\mu+\sigma_{\omega} \frac{\rho k}{\omega}\right) \frac{\partial \omega}{\partial x_{j}}\right]+$ $\frac{\rho \sigma_{d}}{\omega} \frac{\partial k}{\partial x_{j}} \frac{\partial \omega}{\partial x_{j}}$

To study the fluid flow and heat transfer characteristics of different rib cross-sectional shapes in cooling channels, some additional parameters are needed to be defined. They are given as [24]:

Average Nusselt Number:

$N u_{a v}=\frac{h \cdot D_{h}}{k}$

where $h$ and $k$ are average heat transfer coefficient \& thermal conductivity of the working fluid, respectively.

Local Heat Transfer Coefficient $h(x)$ :

$h(x)=\frac{q^{\prime \prime}}{T_{w}(x)-T_{b}}$ 
where $q^{\prime \prime}$ is the uniform heat flux applied at the ribbed wall, $T_{w}(x)$ is the local wall surface temperature, $T_{b}$ is the bulk temperature of the fluid.

Reynolds Number:

$R e=\frac{\rho u_{i n} D_{h}}{\mu}$

where $u_{\text {in }}$ is the inlet velocity of fluid.

$D_{h}$ is the hydraulic diameter of the channel which is defined as:

$D_{h}=\frac{4 A}{P_{w}}$

where $A$ is the cross-section area and $P_{w}$ is the wetted perimeter of the cross-section.

The performance parameter corresponding to the heat transfer is given in terms of Nusselt number:

$F_{N u}=\frac{N u_{a v}}{N u_{0}}$

where $N u_{a v}$ is the average Nusselt number, it is given as the average of the local Nusselt number values.

Local Nusselt number is given as:

$N u=\frac{q^{\prime \prime} D_{h}}{k\left(T_{w}-T_{b}\right)}$

$\mathrm{Nu} 0$ is the Nusselt number for a fully developed flow in a smooth pipe. It is obtained from Dittus-Boelter equation [25], it is given as:

$N u_{0}=0.023 R e^{0.8} \operatorname{Pr}^{0.4}$

The performance parameter related to friction loss is expressed as follows:

$F_{f}=\left(\frac{f}{f_{0}}\right)^{1 / 3}$

where $f$ is the friction loss for the fluid flow over the rough surface. It is given as:

$f=\frac{\Delta P \cdot D_{h}}{2 \rho u_{i n}^{2} p}$

where $\Delta \mathrm{P}$ is the pressure difference between inlet and outlet of the channel \& $p$ is the rib-pitch.

$\Delta P=P_{\text {av,inlet }}-P_{\text {av, outlet }}$

$f_{0}$ is the friction factor for turbulent flow in a smooth pipe. It is derived from Petukhov correlation [26] which is a modified form of Karman-Nikuradse correlation [27] for the range of Reynolds number between $10^{4}$ to $10^{6}$. It is given as:

$f_{0}=2(2.236 \ln R e-4.639)^{-2}$

Blasius relation gives the value of friction factor for fluid flow in a smooth section as given by:

$f=0.316 R e^{-0.25}$

\section{Mesh Convergence and Model Validation}

Figure 3 displays the mesh developed in this research to perform the analysis. Triangular grid system was created to divide the computational domain. Mesh was created using Ansys/Icem. The grids were concentrated near the wall to resolve for high velocity gradient near the wall. To adopt for low Reynolds turbulence models, the starting grid points were positioned at $\mathrm{y}^{+}<1.0$ from the walls. The convergence criteria for the governing equations were set at residual values of $1 \mathrm{e}-6$.

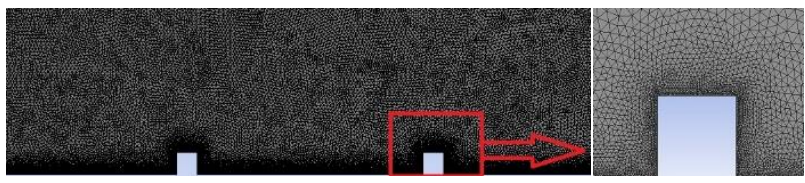

Fig. 3. Developed mesh showing the concentration of grids near the walls

Figure 4 represents the results of wall temperature $\left(T_{w}\right)$ plotted against the channel length $(x)$ for different meshes, for square ribs. It shows the plots of three meshes; coarse, baseline and fine with 19000, 97000 and 193000 number of nodes, respectively. It is observed from the figure that the plots of baseline mesh and fine mesh are almost identical and overlapping each other, which shows the results produced by these meshes are nearly the same with a minor error. The relative percentage difference between the baseline mesh and fine mesh, in terms of ribbed wall temperature, outlet temperature, outlet velocity, Nusselt number and friction factor, is given in Table 1. The relative errors were found to be well under the acceptable range and therefore the baseline mesh with 97000 number of nodes was chosen for the analysis as an acceptable compromise between results accuracy and computational time. The mesh for other rib geometries was constructed with similar grid spacing to the baseline mesh. Air is used as the cooling fluid in this research, Table 2 shows the properties of air.

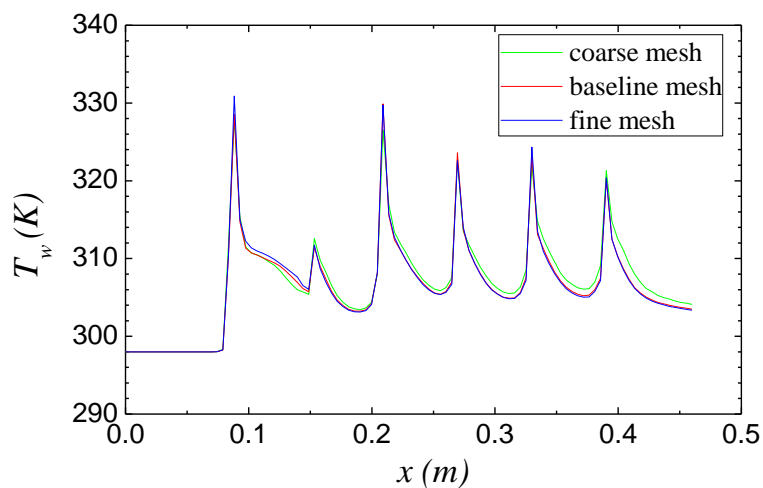

Fig.4. Mesh comparison

Table 1. Relative error between baseline mesh and fine mesh

\begin{tabular}{ll}
\hline Parameter & Percentage Difference (\%) \\
\hline Wall Temperature & 0.18 \\
Outlet Temperature & 0.000020 \\
Outlet Velocity & 0.0035 \\
Heat Transfer Parameter & 0.58 \\
Friction Loss Parameter & 1.53 \\
\hline
\end{tabular}


Table 2. Properties of Air.

\begin{tabular}{lll}
\hline Property & Value & Units \\
\hline Temperature & 298 & $\mathrm{~K}$ \\
Density & 1.1855 & $\mathrm{~kg} / \mathrm{m}^{3}$ \\
Specific Heat Capacity & 1.005 & $\mathrm{~kJ} / \mathrm{kg}-\mathrm{K}$ \\
Thermal Conductivity & 0.02605 & $\mathrm{~W} / \mathrm{m}-\mathrm{K}$ \\
Dynamic Viscosity & $1.868 \times 10^{-5}$ & $\mathrm{~N}-\mathrm{s} / \mathrm{m}^{2}$ \\
Kinematic Viscosity & $15.575 \times 10^{-6}$ & $\mathrm{~m}^{2} / \mathrm{s}$ \\
Prandtl Number & 0.7125 & - \\
\hline
\end{tabular}

Results obtained in this computational study are compared by the theoretical relations as well as the experimental results from the literature. Figure 5 and Figure 6 show the comparison of the results obtained in this work and the DittusBoelter relation and the Blasius relation, respectively, for Reynolds number ranging from 4000 to 20,000 . The maximum variation in comparison with Dittus-Boelter and Blasius is $10 \%$ and $3.2 \%$, respectively.

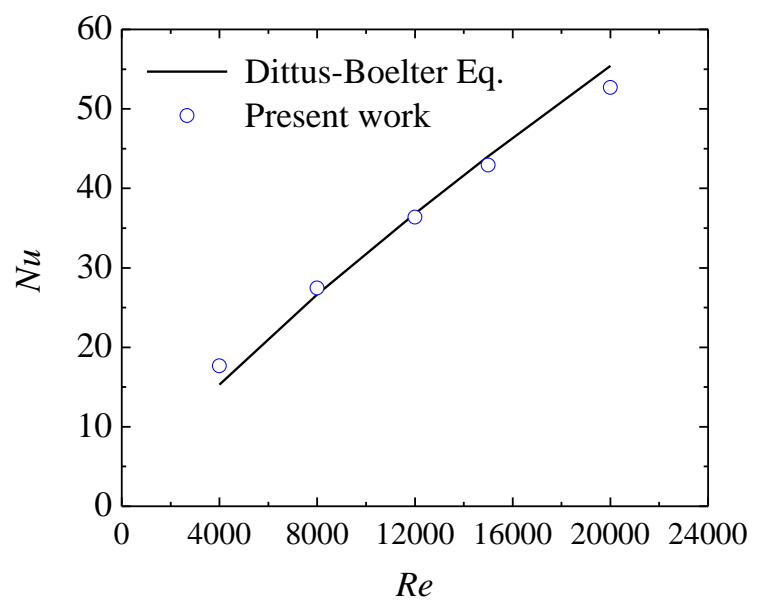

Fig.5. Comparison of present results with Dittus-Boelter relation

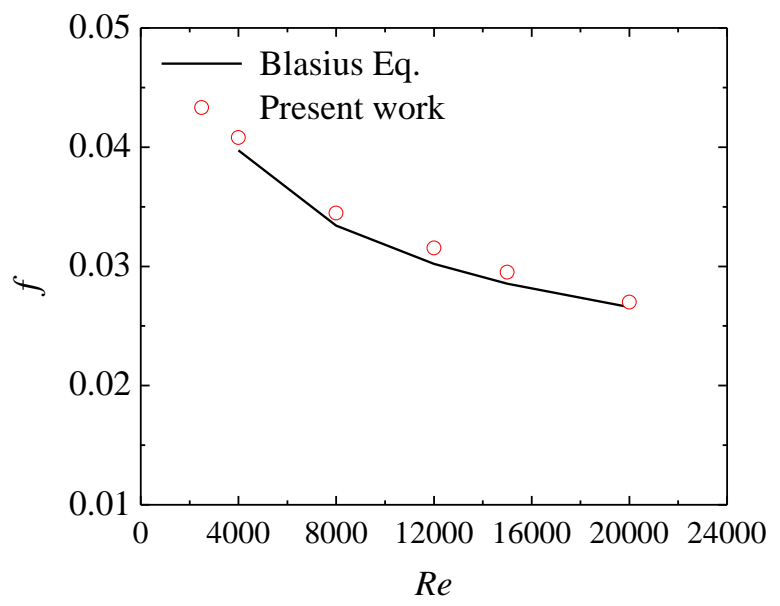

Fig. 6. Comparison of present results with Blasius relation

A ribbed channel installed with square ribs was tested and the numerical results of the analysis were compared with the experimental results of Wang and Sunden [7]. Figure 7 shows the graph of $F_{N u}$ vs $R e$. It shows the experimental line taken from Wang and Sunden's data, which is compared with two turbulence models; $k-\omega$ and SST. The results obtained from $k-\omega$ model were closer to the experimental data at all the Reynolds number, with maximum deviation of $3.7 \%$, hence $k$ - $\omega$ turbulence model was chosen for further simulations.

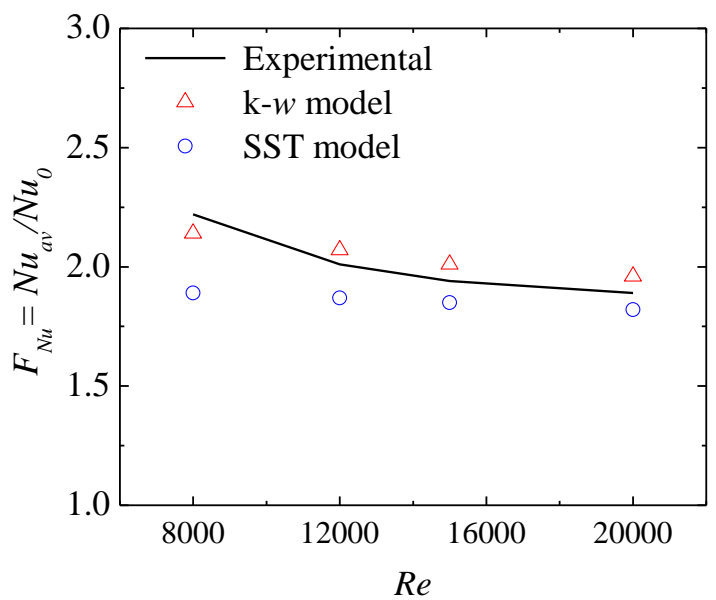

Fig. 7. Validation of numerical results for square ribs compared to experimental data [7].

\section{Results and Discussion}

The effect of rib cross-sectional shape and rib pitch to width ratio on the heat transfer in the channel and obstruction to the flow is numerically studied in this work. Figure 8 displays the comparative results of heat transfer performance parameter $\left(F_{N u}\right)$ for all the ribs tested in this study. Case 1 (square rib) was taken as reference throughout the analysis. As depicted by the figure, case 8 showed the best heat transfer performance whereas case 15 showed the lowest heat transfer performance. Case 2 showed the second-best performance while case 4 showed second worst performance. From this graph it is also observed that Nusselt number certainly depends on the rib shapes.

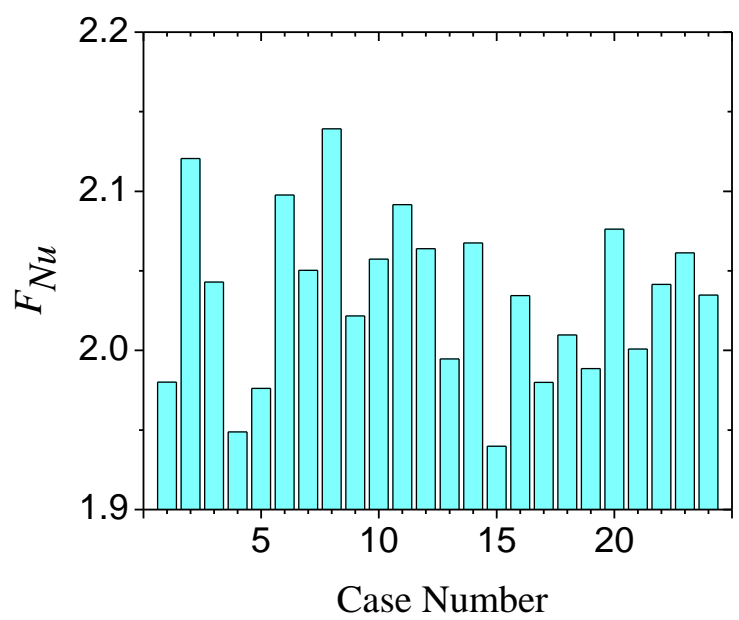

Fig. 8. Heat transfer performance of various rib shapes.

Figure 9 displays the Nusselt number distribution for the three cases discussed above (case 1,8 and 15) along the normalized length of the channel. The trend of the graph is nearly same with slight fluctuations for all the cases. The fluctuation in the trend is due to the geometric differences in the shapes of the ribs. The figure shows that for case 8 the Nusselt number was highest throughout the length of the channel and not just at a specific region, giving it the highest value of average Nusselt number. Case 15 had the lowest Nusselt number 
throughout the length of the channel. Peaks were observed just at the front of the ribs as the ribs cause obstruction in the flow hence increasing the turbulence and Nusselt number.

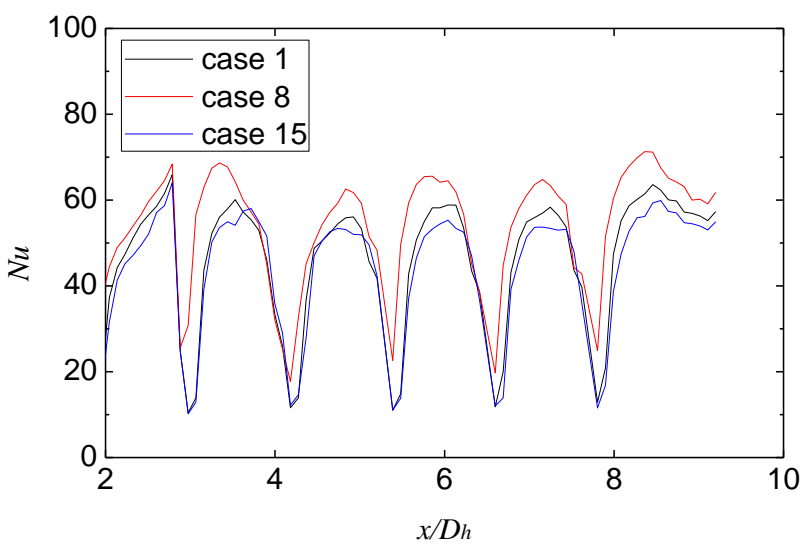

Fig. 9. Distribution of Nusselt number along the normalized length $\left(x / D_{h}\right)$ of the channel for cases 1,8 and 15

Figure 10 shows the effect of pitch to width $(p / e)$ ratio on the Nusselt number, along the Reynolds number in the range of 8000 to 50000 for three ribbed cases, case 1, case 8 (best heat transfer performance) and case 15 (worst heat transfer performance). As the $p / e$ value decreases, the average Nusselt number increases, this is because as the $p / e$ ratio decreases, the number of ribs in the channel increase which increases the turbulence in the channel. For a given rib shape, at a constant value of $p / e$, average Nusselt number increases as the Reynolds number increases. This is because with the increase in Reynolds number, velocity, and turbulence in the channel increases. The average Nusselt number for case 8 is higher than case 1 at all the Reynolds numbers, and that of case 15 is lower than case 1 for all Reynolds numbers, showing that the geometric shape of case 8 induces more turbulence in the channel than case 1 at any given Reynolds number. Case 15 induces least turbulence due to its geometric shape. The difference in the values of average Nusselt number for the three cases is minimum at Reynolds number of 5000 \& maximum at Reynolds number of 50000 . This is because at low Reynolds number, turbulence is less and influence of rib geometry on the turbulence in the channel is not significant, but at high Reynolds numbers the rib geometry influences the turbulence to a much greater extent as shown in the Figure 10.

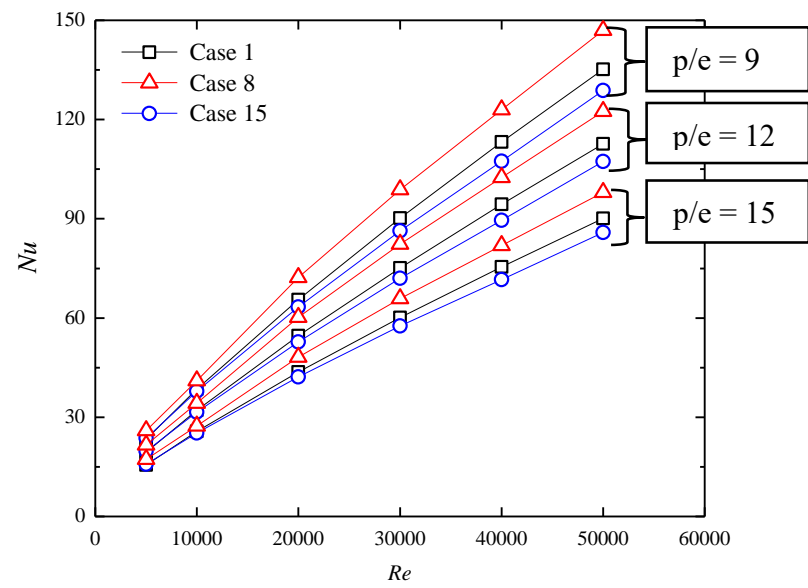

Fig. 10. Effect of Reynolds number and rib pitch to width ratio on average Nusselt number
The temperature contour between $3^{\text {rd }}$ and $4^{\text {th }}$ ribs for the three cases is shown in Figure 11. Hot spots can be seen just behind the ribs due to the separation of flow. It can be observed that case 8 (with highest average Nusselt number) showed smallest size of hot spots and a small area showing hot zone. This is because the geometric shape of case 8 supports good mixing of fluid hence heat transfer rate is high so the area of hot zone is small as seen in the figure. Case 1 and case 15 showed similar trend in temperature distribution just behind the ribs and a similar size hot zone. The geometric shape of ribs of case 8 provides obstruction to the incoming flow due to the front vertical wall which leads to flow separation, but at the same time the slanting back-end face supports the flow reattachment, which is a sign of good mixing, hence the temperature distribution contour shows smallest size of hot spots and small area of hot zone. Case 1 and case 15 have similar design of the back-end face of the rib, which is a vertical wall, it does not support flow reattachment, and therefore hot spots can be observed for these cases.
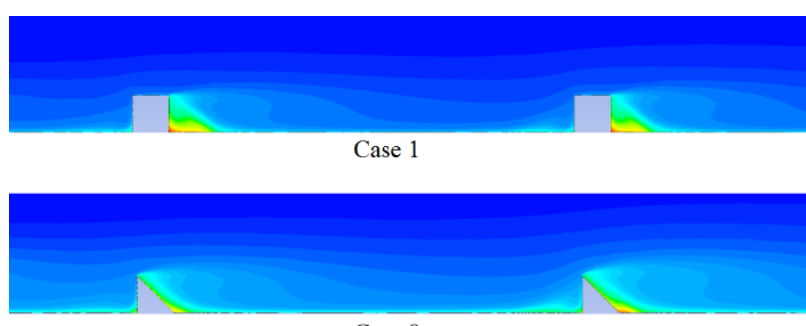

Case 8

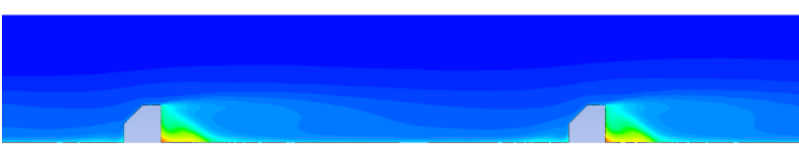

Case 15

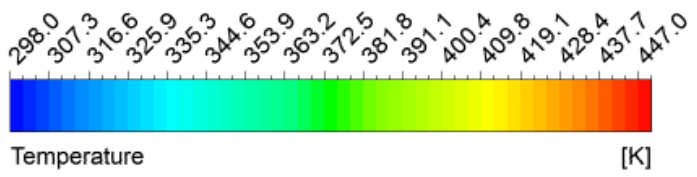

Fig.11. Temperature distribution between $3^{\text {rd }}$ and $4^{\text {th }}$ ribs

The turbulence kinetic energy contour between $3^{\text {rd }}$ and $4^{\text {th }}$ ribs for the three cases; case 1 , case 8 and case 15 is shown in Figure 12. Hot spots can be seen at the front facing wall of the rib due to obstruction to the incoming flow. It can be observed that case 8 (with highest average Nusselt number) showed maximum size of hot spots and the highest value of turbulence kinetic energy compared to the other cases. This is because the geometric shape of case 8 provides obstruction to the incoming flow as it has a vertical front facing wall. Case 1 also has a similar front facing vertical wall, but the turbulence kinetic energy is not similar for case $1 \&$ case 8 because the shape of case 8 also supports reattachment of the fluid just behind the rib, which the case 1 does not. Least value of turbulence kinetic energy is observed in case 15 which cause the incoming flow to jump over the rib due to its slanting front face. It provides least obstruction to the flow and also does not support reattachment of the fluid.

The path of streamlines between $3^{\text {rd }}$ and $4^{\text {th }}$ ribs for the three cases; case 1, case 8 and case 15 is shown in Figure 13. It can be observed that case 8 offers least amount of separation zone as compared to case 1 and case 15 . The rear end of case 8 rib has a sloping edge which supports reattachment of the fluid, so the separation zone is small. Case 1 and case 15 have similar shape at rear end which is a vertical wall, and it causes resistance 
to reattachment of the fluid, so the separation zone is large. Case 15 has the largest separation zone because the front face of the case 15 rib has a sloping edge which causes the streamline to jump over the rib and the rear end is a vertical wall which does not support reattachment of the streamlines.
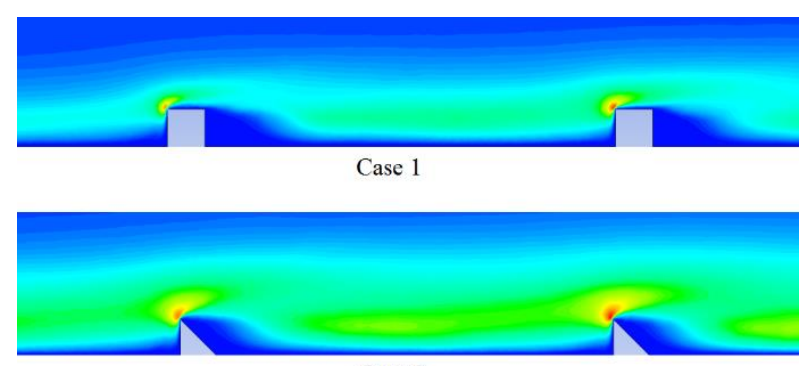

Case 8

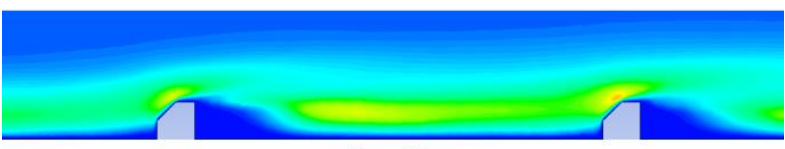

Case 15

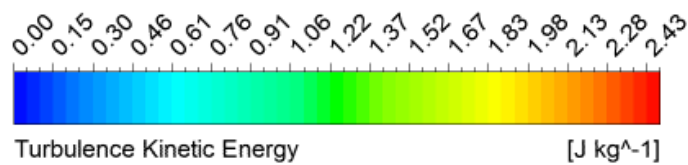

Fig. 12. Turbulence kinetic energy distribution between $3^{\text {rd }}$ and $4^{\text {th }}$ ribs

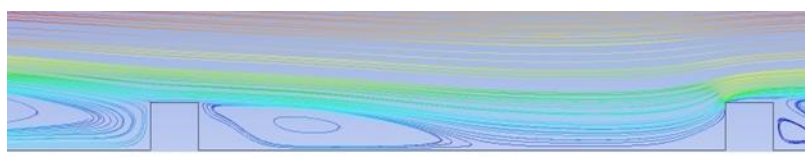

Case 1

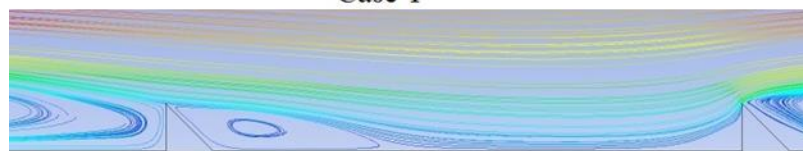

Case 8

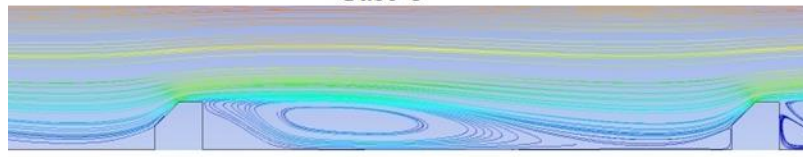

Case 15

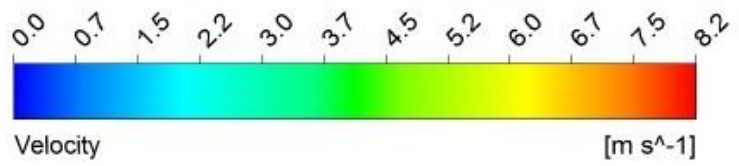

Fig. 13. Streamlines between $3^{\text {rd }}$ and $4^{\text {th }}$ ribs

Figure 14 shows the comparative results of performance parameter related to friction factor $\left(F_{f}\right)$ for all the rib cases tested in this study. The variation in friction factor is entirely due to the different shapes of the ribs. Case 20 showed the highest value of friction factor while case 4 showed the lowest value.

Figure 15 shows the effect of $p / e$ ratio on the friction factor along the Reynolds number ranging from 8000 to 50,000 . Each graph shows the variation of friction factor along Reynolds number for three ribbed cases; case 1, case 4 (lowest value of friction factor) \& case 20 (highest value of friction factor). It is observed that as the $p / e$ value decreases, the value pf friction factor increases, this is because as the $p / e$ ratio decreases, the number of ribs in the channel increase which increases the turbulence in the channel. For a given rib shape, at a constant value of $p / e$, friction factor decreases as the Reynolds number increase, this is because, as the Reynolds number increase, velocity in the channel increases which suppresses the effect of roughness of the channel. At a given value of $p / e$ ratio, the friction factor for case 4 is lower than case 1 at all the Reynolds numbers and the friction factor for case 20 is higher than case 1 for all Reynolds numbers, indicating that the geometric shape of case 4 ribs provides less resistance to the flow as compared to all the other cases, whereas the geometric shape of case 20 provides the most resistance.

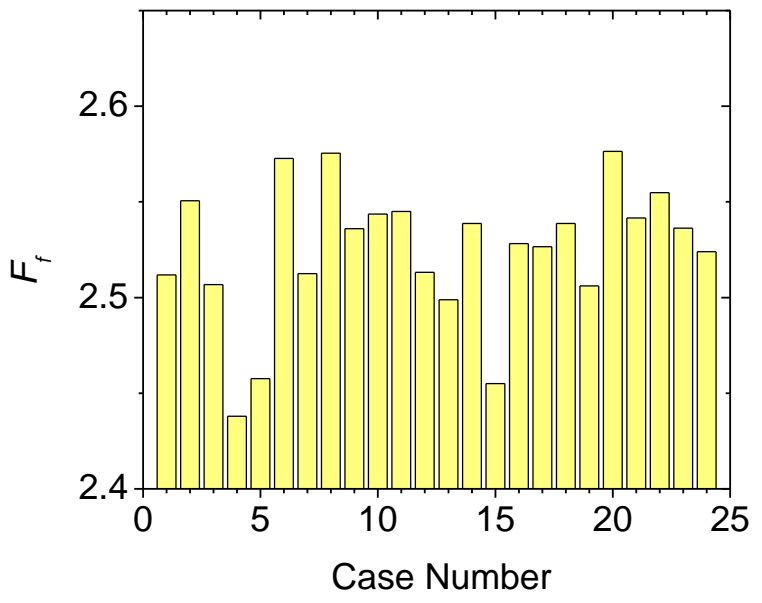

Fig. 14. Comparison of performance parameter related to friction factor $\left(F_{f}\right)$ for various rib shapes

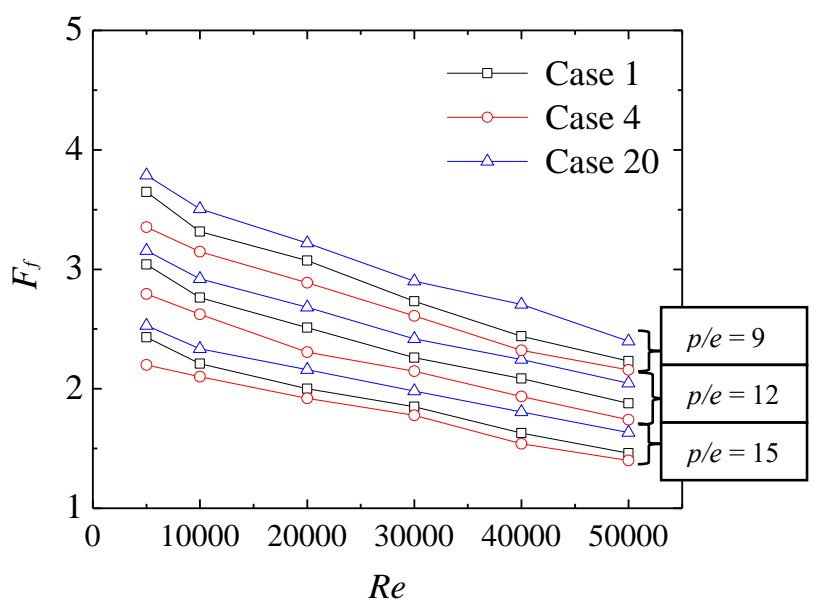

Fig. 15. Effect of Reynolds number and rib pitch to width ratio on friction factor

Streamlines between $3^{\text {rd }}$ and $4^{\text {th }}$ ribs for the three cases; case 1, case 4 and case 20 are shown in Figure 16. It is observed that case 4 offers least resistance to the flow due to its round shape. The streamlines pass smoothly over it, while in the cases 1 and 20 streamlines encounter a straight vertical wall at the front face of the rib. There is a sudden obstruction to the flow in case 1 and case 20 ribs, which causes the friction factor to rise. The size of recirculation zone was lowest in case 4 ribs, and highest in case 20 ribs, but the difference is very less, which suggests that the friction factor not only depends on the recirculation zone and reattachment zone but on other parameters also. 


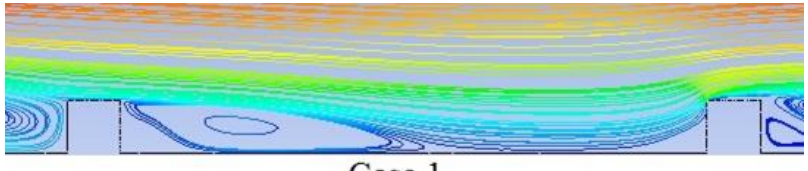

Case 1

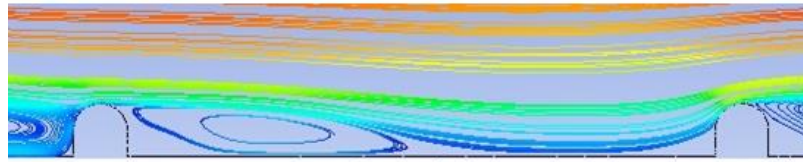

Case 4

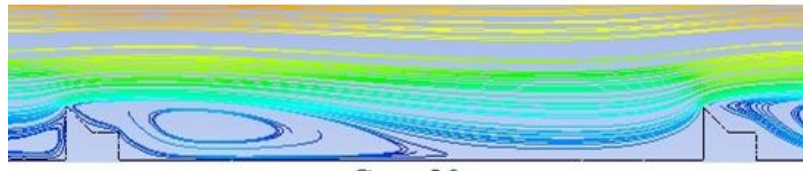

Case 20

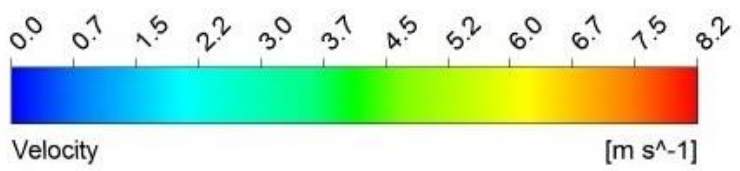

Fig. 16. Streamlines between $3^{\text {rd }}$ and $4^{\text {th }}$ ribs

\section{Conclusion}

In this study, heat transfer performance and fluid flow behavior in a rectangular passage of a gas turbine blade were investigated numerically with air as the working fluid. Twentyfour different rib shapes were tested inside a rectangular channel and the effect of rib shape on the heat transfer \& fluid flow characteristics was studied. The $k$ - $\omega$ turbulence model was adopted for the numerical analysis. The effect of rib pitch to rib width $(p / e)$ ratio was also analyzed. It was observed that the addition of ribs has a significant effect on the performance of the cooling channel. Presence of ribs inside the cooling passage enhances the rate of heat transfer, and the enhancement directly depends upon the shape, size, and pitch of the ribs. Introducing square ribs in a smooth channel caused the Nusselt number to increase by two folds. The highest value of Nusselt number was achieved by incorporating right-angle triangular ribs (case 8) which caused the Nusselt number to increase by further $8 \%$ with an increase in friction factor of $2.5 \%$. The lowest value of friction factor was observed in semicircular ribs (case 4) which was $2.95 \%$ less than the square ribs, however, the Nusselt number was also seen to decrease by $1.5 \%$, as compared to square ribs. The ribs having an upright frontal wall offered better rates of heat transfer, while the ribs having an inclined frontal wall displayed poor heat transfer rates. Heat transfer \& friction loss performances improved with increasing Reynolds number. Decreasing rib pitch-to-width ratio increased the heat transfer performance and friction factor for all the cases.

\section{References}

[1] Islam, M.S., Haga, K., Kaminaga, M., Hino, R., Monde, M., Experimental Analysis Of Turbulent Flow Structure In A Fully Developed Rib-Roughened Rectangular Channel With PIV, Exp. Fluids, 33(296306)(2002)

[2] Gao, X., Sunden, B., Heat Transfer and Pressure Drop Measurements in Rib-Roughened Rectangular Ducts, Experimental Thermal and Fluid Science, 24(2534)(2001).
[3] Chandra, P. R., Alexander, C. R., Han, J. C., Heat Transfer and Friction Behaviors in Rectangular Channels with Varying Number of Ribbed Walls, International Journal of Heat and Mass Transfer, 46(481-495)(2003).

[4] Han, J. C., Park, J.S., Developing Heat Transfer In Rectangular Channels With Rib Turbulators, Int. Journal of Heat and Mass Transfer, 31(183195)(1988).

[5] York, W.D., Holloway, D.S., Leylek, J.H., Prediction Of Heat Transfer In A Ribbed Channel: Evaluation Of Unsteady RANS Methodology, Proceedings of ASME Turbo Expo GT2005-68821(2005).

[6] Thianpong, C., Chompookham, T., Skullong, S., Promvonge, P., Thermal Characterization of Turbulent Flow in a Channel with Isosceles Triangular Ribs, International Communications in Heat and Mass Transfer, 36(712-717)(2009).

[7] Wang, L., Sunden, B., Experimental Investigation of Local Heat Transfer in a Square Duct with VariousShaped Ribs, International Journal of Heat and Mass Transfer, 43(759-766)(2007).

[8] Kamali, R. and Binesh, A., The Importance of Rib Shape Effects on the Local Heat Transfer and Flow Friction Characteristics of Square Ducts with Ribbed Internal Surfaces, International Communications in Heat and Mass Transfer, 35(8)(1032-1040)(2008).

[9] Promvonge, P., Thianpong, C., Thermal Performance Assessment of Turbulent Channel Flows Over Different Shaped Ribs, International Communications in Heat and Mass Transfer, 35(1327-1334)(2008).

[10] Eiamsa-ard, S., Promvonge, P., Thermal Characteristics Of Turbulent Rib-Grooved Channel Flows, International Communications in Heat and Mass Transfer, 36(7)(705-711)(2009).

[11] Chaube, A., Sahoo, P.K., Solanki, S.C., Analysis Of Heat Transfer Augmentation And Flow Characteristics Due To Rib Roughness Over Absorber Plate Of A Solar Air Heater, Renewable Energy, 31(3)(317-331)(2006).

[12] Wongcharee, K., Changcharoen, W., Eiamsa-ard, S., Numerical Investigation Of Flow Friction And Heat Transfer In A Channel With Various Shaped Ribs Mounted On Two Opposite Ribbed Walls, International Journal of Chemical Reactor Engineering, 9(Article A26)(2011).

[13] Manca, O., Nardini, S., Ricci, D., A Two-Dimensional Numerical Investigation On Forced Convection In Channels With Transversal Ribs, ASME Conference Proceedings, (43826)( 1099-1107)(2009).

[14] Manca, O., Nardini, S., Ricci, D., Numerical Analysis Of Water Forced Convection In Channels With Differently Shaped Transverse Ribs, Journal of Applied Mathematics, 211(Article ID 323485)(2011).

[15] Jia, R., Sunden, B., Prediction Of Turbulent Heat Transfer And Fluid Flow In 2D Channels Roughened By Square And Deformed Ribs, Proceedings of ASME Turbo Expo, 5(143-152)(2003).

[16] Shokouhmand, H., Vahidkhah, K., Esmaeili, M.A., Numerical Analysis Of Air Flow And Conjugated Heat Transfer In Internally Grooved Parallel-Plate Channels, World Academy of Science, Engineering and Technology, 73(2011).

[17] Moon, M. A., Park, M. J., Kim, K. Y., Evaluation of Heat Transfer Performances of Various Rib Shapes, International Journal of Heat and Mass Transfer, 71(275-284)(2014). 
[18] ANSYS FLUENT 12.1 Theory Guide, ANSYS Inc., Canonsburg, Pennsylvania, (2010).

[19] Eiamsa-ard, S., Promvonge, P., Numerical Study On Heat Transfer Of Turbulent Channel Flow Over Periodic Grooves, International Communications in Heat and Mass Transfer, 35(7)(844-852)(2008).

[20] Seo, J. W., Afzal, A., Kim K. Y., Efficient MultiObjective Optimization of a Boot-Shaped Rib in a Cooling Channel, International Journal of Thermal Sciences, 106(122-133)(2016).

[21] Wilcox, D.C., Multiscale Model For Turbulent Flows, 24th Aerospace Science Meeting, American Institution of Aeronautics and Astronautics Journal, (1986).

[22] Menter, F.R., Two-Equation Eddy Viscosity Turbulence Models For Engineering Applications,
American Institution of Aeronautics and Astronautics Journal, 32(1595-1605)(1994).

[23] Wilcox, D. C., Formulation Of The k- $\omega$ Turbulence Model Revisited, American Institution of Aeronautics and Astronautics Journal, 46 (11)(2823-2838)(2008).

[24] Manca, O., Nardini, S., Ricci, D., A Numerical Study Of Nanofluid Forced Convection In Ribbed Channels, Applied Thermal Engineering, 37(280-292)(2012).

[25] Dittus, F.W., Boelter, L.M., Heat Transfer in Automobile Radiators of the Turbulator Type, University of California, Berkeley Publication, 2(443461)(1930).

[26] Petukhov, B.S., Advances in Heat Transfer, Academic Press, New York, 6(503-504)(1970)

[27] Schlichting, H., Boundary Layer Theory, $6^{\text {th }}$ edition, McGraw Hill, (1968). 